\title{
Impact of Peer-mediated Learning on Achievement and Motivation in Computer Science among Senior Secondary School Students in Minna Metropolis, Niger State
}

\author{
Rosemary Ogechi Ohadugha \\ Dept. of Educational Technology, Federal University of Technology, Minna, Niger State, Nigeria \\ ORCID: 0000-0003-2687-1579 \\ Emeka Joshua Chukwuemeka \\ Dept. of Educational Technology, Federal University of Technology, Minna, Niger State, Nigeria \\ ORCID: 0000-0002-1985-8002 \\ Abdullateef Eyitayo Babatunde \\ Dept. of Educational Technology, Federal University of Technology, Minna, Niger State, Nigeria \\ ORCID: 0000-0002-2913-3670
}

\begin{abstract}
The study examined the Impact of Peer-Mediated Learning on achievement and motivation in computer science among senior secondary school students in Minna metropolis, Niger state. The study adopted a randomized pre-test, post-test control group design. Two hypotheses were formulated to guide the study. Purposive sampling technique was used to select four (4) Private Secondary Schools from Minna, Metropolis. Eighty (80) Students were drawn from the four Secondary Schools as sample size through stratified random sampling technique. Validated Test Instrument; Basic Computer Skills Acquisition Test (BCSAT) and Questionnaire: Motivated Strategy for Learning Questionnaire (MSLQ) vetted by experts from Computer Science and Educational Technology Departments were used for data collection. The BCSAT was made up of 20 items multiple-choice objective test questions to test students' cognitive knowledge and 5 practical questions, each comprising steps that tested students' computer practical skills while MSLQ, a Likert scale with 31 items was used to determine the motivational beliefs of students taught computer skills. ANOVA and Kruskal Wallis $\mathrm{H}$ test was used for data analysis and was tested at 0.05 level of significance. The study revealed that there was a statistically significant difference in the mean scores of students taught using Peer-Mediated Learning (PML) than those taught using conventional method. The study further revealed that students' motivation towards PML were significantly positive when compared to the students taught using conventional method. Based on these findings, the researchers recommended that Secondary Schools should adopt PML for effective teaching and learning of computer skills related concepts in Computer Science.
\end{abstract}

Keywords: peer-mediated learning, motivation, computer skills

\section{INTRODUCTION}

In recent times, technology has become necessary as countries and organisations around the world continue to devise means of gaining a competitive edge over the others. Given this scenario, Computer education is of utmost importance, thus, making most countries around the world sought to introduce the study of computer science in their educational system from primary through to tertiary institutions. Computer science 
basically impact students with basic skills they require to stay computer literate and solve problems (Hawi, 2010). In essence computer science is essential, and this is because it adds to the success of students in a digital and inter-connected world. Moreover, acquiring computer knowledge has become necessary since the use of computers and computer technologies as well as data and digital computing have become an essential part of most disciplines around the world (Yang, Hwang, Yang, \& Hwang, 2015).

The need to impact the Nigerian primary and secondary schools' students with computer skills cannot be overemphasised. That is why the Federal Government of Nigeria, through the national policy on education (Federal Republic of Nigeria, 2013), has continued to reiterate its commitment through the national policy to enhance computer literacy in the educational sector in Nigeria. Unfortunately, Arugu and Chilaka, (2016) posited that Africa and indeed Nigeria is still lagging behind in computer applications and usage. Furthermore, Brent (2005) argued that the ability of students to acquire the proper skill lies strictly on the instructional strategy used, adding that in any learning process, students' activity should be emphasised more than the instruction. In order words, it should be engaging and also be able to meet the students learning needs since students differ in their learning capacities.

The impact of Individual difference when it comes to human learning cannot be overlooked at any stage in life. It is therefore required that teachers design learning activities that are capable of addressing the individual needs of students. There are need-based learning activities that can take the form of discussion, group work, mentoring or peer-mediated learning. These methods according to Ali, Anwer, and Jaffar (2015) are usually adopted to enhance students' learning. Peer Mediated Learning (PML) is an interactive strategy used in the teaching and learning process where students learn with or without the immediate intervention of a teacher (Crouch \& Mazur, 2001). As far as PML is concerned, it is a teaching strategy where a group of students interact with one another in order to help each other learn and this is often done by one student occupying the role of tutor while the other the role of tutee. PML among students is useful in acquiring new skills, knowledge as well as proffering solutions to each other's problems by talking, playing, and sharing ideas (Bombardelli, 2016). It is therefore a flexible, supported and strongly researched based practice that aid students in reviewing academic or behavioral concepts (Hott \& Walker, 2012).

The objectives of PML according to Bowman-Perrott, Davis, Vannest, Williams, Greenwood and Parker (2013), is to significantly increase the time students spend on a task and to provide an avenue where students sufficiently get the chance to show their level of understanding on a skill through increased and immediate feedback. These components have empirical link to enhanced social interaction among students as well as students increased academic achievement (Bowman-Perrott et al., 2013). An experimental study conducted on the effect of peer learning on students' academic achievement in Home Economics in Dunukofia, Local Government Area of Anambra by Okoye (2013), revealed that 95 students taught with peer learning obtained a mean score of 56.20 which was significantly higher than the students in the control group that obtained a mean score of 40.27. Another experimental research conducted by Jibrin and Zayum (2012) on the effect of Peer Tutoring Instructional Method on the academic achievement in Biology among 105 secondary school students in Zaria Metropolis, showed that the mean achievement scores of students' taught using this method was 12.22 compare to students in the control group whose mean score was 6.58 . The result showed that students who interacted with their peers performed better than the students exposed to traditional method of teaching. In agreement, Okilwa and Shelby (2010) reiterated that one of the benefits of PML is that it allows students to receive one on one assistance from one another, adding that it helps to promote the transfer of acquired skills from school, home and workplace. Lord (2001) additionally offered that students who work in groups tend to have better test scores in areas like critical thinking skills and reasoning. This is because they get to work together as a team and also explain concepts to one another in their own words which is a good learning technique and source of motivation.

Motivation is that action taken by an individual as a result of one's drive or willingness to exhibit a certain behaviour or to move towards achieving a particular goal (Soltanzadeh, Hashemi, \& Shahi, 2013). Motivation according to Adedeji (2007) it is the state at which a question is raised as to why an individual behaves or does things the way they do them. It is that zeal students have to keep going towards a particular direction or that which energizes them to do something or make them sustain a particular behaviour (Reeve, 2006). 
Over the years, learning and motivation have been considered to be two variables for joint analysis. This is because of the significant role played by motivation in students' academic achievement (Rusillo \& Arias 2004). In order words, students increase their effort or energy as a result of the motivation they have towards achieving a task which increases their persistence and sustains their action (Ormrod, 2014).

From the viewpoints of Pintrich and Schunk (2002), students' motivation has a direct link to learning and setting, stressing that modern pedagogical strategies need to be adopted in order to understand how students develop the capacity to regulate their own learning. Similarly, motivational beliefs according to Pintrich et al. (2002) is positively related to higher level of self-regulated learning adding that when students monitor the outcome of their learning strategies, their learning becomes self-regulated which will in turn increase their motivation and academic performance.

This notion was supported by Yukselturk and Bulut (2007) who stated that motivation is a fundamental recipe for academic success. In other words, student' motivation and learning strategy used have relative impact on students' performance. These learning strategies include time and study environment, rehearsal, organisation, critical thinking, help seeking and peer learning. Harper and Meheady (2007) were in agreement when they posited that when peers interact in a learning environment, they are usually at ease, open and free to express themselves irrespective of their geographical background, social class or age limit. In addition, the responses they offer to one another reinforces them to put the corrective practices into action. The above statement was also in line with the findings of Ormrod (2014) who reported that motivation enhances performance because students who are motivated develop goal-directed behaviours, persistence, effort and energy and these attributes lead to improved performance.

On the other hand, Marcou, and Philippou, (2005), reported that students' active engagement in a learning process increases when the students trust their own capabilities, develop high selfefficacy expectation, value their tasks and feel responsible for the learning objectives before them. In other words, these attributes can influence students' cognitive and metacognitive processes when they are approached with a task. In other words, increasing the chances of student's higher performance requires instruction that will get them fully motivated and engaged with no or less divided attention (Pinantoan, 2016). That is to say, students require teaching methods that will keep them motivated and enhance their learning skills.

\section{Statement of the Research Problem}

Despite the predictions made by the National Policy on computer to make the Nigerian society computer literate by introducing the subject, Computer Science, into primary schools and secondary schools, the agenda is yet to make a visible impact in the students' computer literacy skills. An investigation into students' competence in the use of computer applications revealed that Nigerian schools are mostly dominated with the chalkboard and textbook method of teaching with little or no interaction in the classroom. This drawback can be attributed to teaching strategy predominantly applied by teachers which is the conventional lecturebased method. This consequently leads to students who become easily bored and less attentive during classes. This in the long run if not reversed may stand as a huge setback for students who would require computer skills to gain admission into the universities or fit into computer related schools/course where the use of computer and the internet to compose notes, make presentation, conduct internet research and communicate with their teachers via email is highly competitive (Oladunjoye \& Benwari, 2014). Despite this challenge, Nigerian students still need to acquire computer skills. This study therefore is aimed at determining the impact of peer-mediated learning on achievement and motivation in computer science among senior secondary school students in Minna metropolis, Niger state.

\section{Research Questions}

The following are the research questions raise to guide this study:

1. Is there any difference in the computer skills of students taught using Peer-mediated Learning (PML) and those taught using conventional teaching method? 
2. Is there any difference in the motivation of students taught using PML and those taught using conventional teaching method?

\section{Research Hypotheses}

HO1: There will is no significant difference in the computer skills of students taught using Peermediated Learning (PML) and those taught using conventional teaching method

HO2: There is no significant difference in the motivation of students taught using PML and those taught using conventional teaching method.

\section{METHODOLOGY}

\section{Population and Sample}

The research design adopted for this research was a pre-test, post-test, control group design. The population of this study was the entire Senior Secondary School Students (841) of 2016/2017 in 31 Private Schools in Minna Metropolis, Niger State. Private Secondary Schools were the focus in this study. Purposive sampling was used to sample four (4) private secondary schools in Minna Metropolis. The sample of this study comprised of 80 Senior Secondary School Two Students (SSII).

\section{Sampling Technique}

The technique used for the selection of students was a simple random sampling. Students were first stratified based on gender, then ten (10) students were selected using the hat draw method in which 10 pieces of paper were written 'Yes' and others 'No' separately for male and female. Those that picked 'Yes' were selected while those that picked 'No' were dropped. This gave a sample size of 20 students ( 10 males and 10 females) from each of the secondary schools and a total sample size of $80 \mathrm{SSII}$ students ( 40 males and 40 females).

\section{Instrument}

Two instruments were designed by the researchers for data collection. The instruments for the study includes; Treatment Instrument, Test Instrument and a Questionnaire. The treatment instruments were the; Basic Computer Skill Instructional Power Point DVD Package and Classwide Peer-mediated Drill and Practice (CWPMDP). The test instrument was the Basic Computer Skill Acquisition Test (BCSAT) while the questionnaire was Motivated Strategy for Learning Questionnaire (MSLQ). Basic Computer Skill Instructional Power Point DVD Package was a self-study instructional power point presentation that contained the instruction on computer science to be learned by students in the experimental group.

The classroom for the experimental group was flipped and the purpose of the instructional power point presentation on the DVD package was to allow the students have pre-existing knowledge on what they would learn interactively in the class as peers as this formed the basis for their learning. On the other hand, Classwide Peer-mediated Drill and Practice is an In-class game activity with a planned question and answer session that allowed the tutor and tutee in the experimental group to engage themselves in a cooperative learning activity in the classroom after they have used the Basic Computer Skill Instructional Power Point DVD to learn individually at home.

Basic Computer Skill Acquisition Test (BCSAT) contained questions drawn from related WASCE past questions papers on Computer Science. The test instrument has two sections. Section A which contained twenty (20) items multiple choice questions was aimed at testing students' theoretical knowledge while section B which had five questions, each containing practical demonstrative steps aimed at testing students' psychomotor skills as well as their practical utilization of the computer which covered topics on Word Processor, the Internet and Email. To ensure the face and content validity of BCSAT, it was vetted by five experts in Computer Science and Educational Technology Department in Federal University of Technology, Niger State. The researchers equally established the reliability of the instrument through a pilot study. The result obtained 
Table 1. ANOVA Comparison of Test Scores of Experimental and Control Groups

\begin{tabular}{lccccc}
\hline Source of Variation & Sum of Squares & Df & Mean Square & F cal. & P \\
\hline Between Groups & 2060.450 & 1 & 2060.450 & $172.905^{*}$ & .000 \\
Within Groups & 929.500 & 78 & 11.917 & & \\
Total & 2989.950 & 79 & & & \\
\hline
\end{tabular}

*Significant at 0.05 level

from the BCSAT was analysed using Kuda Richardson 20 (K-R20). A reliability co-efficient of 0.78 was obtained and from the result analysed, it showed that the instrument was reliable for this study.

Motivated strategy for learning questionnaire (MSLQ) is an adapted self- report questionnaire and this study used it to ascertain students' motivation towards learning the computer skills through a learning strategy called Peer-Mediated Learning (PML). The thirty-one scale items were made up of three general constructs that included; Value components, Expectancy components and Affective components. The options in the questionnaire ranked from 1 to 5 .

Number 5 represented strongly agree, 4 represented agree, 3 represented I do not know, 2 represented disagree while 1 represented strongly disagree. To ensure the face and content validity of MSLQ, it was vetted by three experts in Educational Technology Department in Federal University of Technology, Niger State. The researchers equally established the reliability of the instrument through a pilot study. This yielded result a reliability coefficient of 0.82 using Cronbach Alpha.

A period of eight (8) weeks was used for data collection. During the first and second (1st and 2 nd) weeks of the study, pre-test was administered to all the groups to determine the equivalence of both the experimental and control group before the treatment. Afterwards, MSLQ was administered to the two groups to determine their initial motivation before the treatment. On the third to sixth (3rd to 6th) weeks, actual teaching and learning commenced for both groups. While students in the control group learned in class using the conventional teaching method, students in the experimental group had their classroom flipped.

On the seventh (7th) week, revision was done by the two groups and on the eighth (8th) week Basic Computer Skill Acquisition Test (BCSAT) and Motivated Strategy for Learning Questionnaire (MSLQ) was administered to the students in the two groups.

\section{DATA ANALYSIS AND RESULTS}

The data collected were collated and analysed using analysis of variance (ANOVA) and Kruskal Wallis $\mathrm{H}$ test statistic. The result of the analysis provided answers to the two null hypotheses respectively presented in Tables 1 and 2.

\section{Hypothesis One}

$\mathrm{HO}_{1}$ There is no significant difference in the acquisition of computer skills of students taught using PeerMediated Learning (PML) and those taught using conventional teaching method.

Table 1 shows the ANOVA result on the comparison of post-test scores of students in the experimental and control groups. The result on the table shows a difference between the two groups at 0.05 level of significance $(F(1,79)=172.905, p<0.05)$. Based on this finding, null hypothesis one was rejected. This implies that there was a statistically significant difference in the achievement mean scores of students taught computer skills using PML and those taught with conventional teaching method.

\section{Hypothesis Two}

$\mathrm{HO}_{2}$ There is no significant difference in the motivation of students taught using PML and those taught using conventional teaching method. 
Table 2. Kruskal Wallis H Test Comparison of Motivational Scores of Experimental and Control Group

\begin{tabular}{lccccc}
\hline Group & $\mathrm{N}$ & Mean Rank & Df & Chi-square & P-value \\
\hline Experimental & 40 & 44.34 & 1 & 31.410 & $0.00^{*}$ \\
Control & 40 & 18.66 & & & \\
\hline
\end{tabular}

*Significant at 0.05

Research Question 2: Findings on perceptions of teachers towards the use of high-tech assistive technology resources in teaching and learning of students with physical disabilities in special education schools in NorthWest Nigeria.

Table 2 shows the Kruskal Wallis $\mathrm{H}$ test result on the comparison of motivational scores of students in both experimental and control groups. The table shows a significant main effect in the mean motivation scores of the two groups $(\mathrm{X} 2(1)=31.410, \mathrm{P}=0.00)$ with a mean rank motivation score of 44.34 for experimental group and 18.66 for control group. Based on this finding, null hypothesis three was rejected. This implies that there was a statistically significant difference in the motivational scores of students taught computer skills using PML and those taught with conventional method.

\section{DISCUSSION OF FINDINGS}

Findings of this study on the Impact of Peer-Mediated Learning shows that there was a significant impact on the post-test achievement scores of students taught Computer Skills. Students taught using PML achieved significantly better than their counterpart who were taught using conventional method. This finding was supported by the study of Okoye (2013) where the result revealed that 95 students taught with Peer Tutoring Method obtained a mean score of 56.20 which was significantly higher than the students in the control group that obtained a mean score of 40.27 . Also supporting this result is the research by Jibrin and Zayum (2012) on the effect of Peer Tutoring Instructional Method on the academic achievement on Biology which showed the mean achievement score of students' taught using Peer Tutoring Instructional Method to be 12.22 which was higher when compared to the mean score of students in the control group which was 6.58. The results therefore showed that students who were taught using PML achieved better performance than does exposed to conventional method of teaching.

Finding on the impact of PML on motivation of students taught computer skills using PML and those taught using conventional teaching method revealed that there was a difference between the results of two groups. The experimental group had higher motivational scores of 3.462 and a standard deviation of .531 while control group had motivational scores of 1.50 and a standard deviation of .504 revealing motivational score difference of 1.962. This indicated that students who were taught computer skills using PML were more motivated than their counterparts who were taught using conventional teaching method. The finding of this study agreed with the findings of Harper et al. (2007) who reported that when peers interact in a learning environment, they are usually at ease, open and free to express themselves irrespective of their geographical background, social class or age limit. The result is also in agreement with the findings of Ormrod (2014) who reported that motivation enhances performance because students who are motivated develop goal-directed behaviours, persistence, effort and energy and these attributes lead to improved performance.

\section{CONCLUSION}

Peer-Mediated Learning (PML) in this study produced significantly better performance in students' Basic Computer Skill Acquisition than students taught using conventional method. Thus, PML is an effective teaching and learning strategy for students in secondary school and should be embraced by computer science teachers in Nigerian secondary schools. 


\section{RECOMMENDATIONS}

Based on the findings of this study, the following recommendations were given:

1. Teachers should spend time in training the students on how to work in pairs and coach them in order for them to effectively achieve corrective feedbacks from PML sessions.

2. Plans should be made by school administrators on how to expose computer science teachers to training, workshops and seminars on the use of PML modes of instruction.

3. Stake holders in the educational sector should endeavour to make use of these findings and research ways to put into place educational policies that will improve computer literacy in Nigeria.

\section{REFERENCES}

Adedeji, T. (2007). The impact of motivation on students' academic achievement and learning outcome in Mathematics among secondary school students in Nigeria. Eurasia Journal 3(2), 149-156. https://doi.org/10.12973/ejmste/75390

Ali, N., Anwer, M., \& Jaffar, A. (2015). Impact of peer tutoring on learning of students. Journal Stud. Manag. Plan. 1, 61-66.

Arugu, O. L., \& Chilaka, F. C. (2016). Information and Communication Technology (ICT) Application in Social and Political system. European Journal of Research in Social Science, 4(1) 222-555.

Bombardelli, O. (2016). Effective Teaching Practice: Peer Tutoring in Education for Active Citizenship. Eur. Proc. Soc. Behav. Sci, 343-355. https://doi.org/10.15405/epsbs.2016.11.36

Bowman-Perrott, L., Davis, H., Vannest, K., Williams, L., Greenwood, C., \& Parker, R. (2013). Academic benefits of Peer Tutoring. A Meta- Analytic Review of single case research. School Psychology Review, 42(1), 39-55.

Brent, R. (2005). Understanding students' differences. Journal of Engineering Education, 94(1) 57-72. https://doi.org/10.1002/j.2168-9830.2005.tb00829.x

Crouch, C. H., \& Mazur, E. (2001) Peer Instruction; 10 years of experience and result. American Journal of Physics, 69(9), 970-977. https://doi.org/10.1119/1.1374249

Federal Republic of Nigeria. (2013). National Policy on Education (4th Ed.). Educational Research and Development Council. Lagos, Nigerian.

Harper, G. F., \& Meheady, L. (2007). Peer-mediated teaching and students with learning disabilities. Intervention in schools and clinic, 43, 101-107. https://doi.org/10.1177/10534512070430020101

Hawi, H. (2010). Causal attributions of success and failure made by undergraduate students in an introductory-level computer programming course. Computers \& Education, 54, 1127-1136. https://doi.org/10.1016/j.compedu.2009.10.020

Hott, B., \& Walker, J., (2012). Peer Tutoring. Retrieved from http://www.councilforlearnigdisabilities.org/publications/infosheets

Jibrin, A. G., \& Zayum, S. D. (2012). Effects of peer tutoring instructional method on the academic achievement in Biology among secondary school students in Zaria metropolis, Nigeria. Science Education Programme. Abubakar Tafawa Balewa University, Bauchi, Nigeria.

Lord, T. (2001). 101 reasons for using cooperative learning in Biology teaching. The American Biology Teachers, 63(1), 30-38. https://doi.org/10.2307/4451027 
Marcou, A., \& Philippou, G. (2005). Motivational Beliefs, Self-regulated Learning and Mathematical problemsolving. Group for Psychology of Mathematics Education, 3, 297-304.

Okilwa, N. S., \& Shelby, L. (2010). The effect of Peer Tutoring on academic performance of students with disabilities in grade 6 through 12. Remedial and Special Education, 31, 450-463. https://doi.org/10.1177/0741932509355991

Okoye, A. A (2013). Effect of peer tutoring method on students' academic achievement in Home Economics. Academic Journal of interdisciplinary studies, 2. (5). Published by MCSER-CEMAS-Sapienza, University of Rome.

Oladunjoye, P., \& Benwari, N. N. (2014). Computer literacy among undergraduate students in Nigeria $\begin{array}{lllll}\text { Universities. } & \text { British Journal of }\end{array}$ https://doi.org/10.18488/journal.61/2014.2.8/61.8.184.191

Ormrod, J. E. (2014). How motivation affects learning and behaviour. Excerpt for Educational Psychology developing Learners, 384-386.

Pinantoan, A. (2016). Introduction to learning strategies. Retrieved from http://www.opencolleges.edu.au/informed/teacher.resources/teaching-strategies

Pintrich, P. R., \& Schunk, D. A. (2002). Motivation in Education. New York: Prentice Hall.

Reeve, J. (2006). Autonomy, volitional motivation and wellness. Motivation and Emotion, 30(1) 257-258. https://doi.org/10.1007/s11031-006-9050-9

Rusillo, A. T. C., \& Arias, P. F. C. (2004). Gender Differences in Academic Motivation of Secondary School Students. Electrical Journal of Research in Educational Psychology, 2(1), 97-112.

Soltanzadeh, L., Hashemi, S. R. N., \& Shahi, S. (2013). The effect of active learning on academic achievement and motivation in high school students. Archive of applied science research, 5(6) 127-131. Retrieved from http://scholasresearchlibrary.com/archive.html

Yang, T. C., Hwang, G. J., Yang, S. J. H., \& Hwang, G. H. (2015). A Two-Tier Test-based Approach to Improving Students' Computer-Programming Skills in a Web-Based Learning Environment. Educational Technology and Society, 18(1), 198-210.

Yukselturk, A., \& Bulut, S. (2007). Predictors for Students Success in an Online Course. Educational Technology and Society, 10, 71-83.

Correspondence: Emeka Joshua Chukwuemeka, Dept of Educational Technology, Federal University of Technology, Minna, Niger State, Nigeria. E-mail: emekac.joshua@gmail.com 